\title{
Time-series measurements of oxygen consumption of copepod nauplii
}

\author{
Marion Köster $^{1, *}$, Christian Krause ${ }^{2}$, Gustav-Adolf Paffenhöfer ${ }^{3}$ \\ ${ }^{1}$ Institut für Ökologie der Ernst-Moritz-Arndt-Universität Greifswald, Schwedenhagen 6, 18565 Kloster/Hiddensee, Germany \\ ${ }^{2}$ Presens Precision Sensing GmbH, Josef-Engert-Str. 11, 93053 Regensburg, Germany \\ ${ }^{3}$ Skidaway Institute of Oceanography, 10 Ocean Science Circle, Savannah, Georgia 31411, USA
}

\begin{abstract}
The goal of this study was to determine over time with high temporal resolution the oxygen consumption rates of nauplii of marine planktonic copepods while feeding on phytoplankton at environmental concentrations. The determination of the nauplii's oxygen consumption was achieved by applying a fluorescence-based non-invasive technology. The hourly oxygen consumption at $21^{\circ} \mathrm{C}$ ranged from near $18 \mathrm{nl} \mathrm{O}{ }_{2}$ Nauplius $\mathrm{IV}^{-1}$ to about $33 \mathrm{nl} \mathrm{O} 2$ Nauplius $\mathrm{VI}^{-1}$ of the calanoid Eucalanus pileatus. The nauplii's feeding activity was reflected by an average reduction of food concentration of about $50 \%$ of the initial abundance and a production of 2.2 pellets nauplius ${ }^{-1} \mathrm{~h}^{-1}$. The nauplii's average food consumption, at a rate equal to $17.7 \%$ of body weight $\mathrm{d}^{-1}$, did not cover their metabolic expenses of $29.7 \%$ of body weight $\mathrm{d}^{-1}$. Their feeding performance could have been to some extent limited by the size of the experimental vessels. Microscopic observations showed that the motion of late nauplii of E. pileatus was continuous (i.e. as previously observed) in vessels of $250 \mathrm{ml}$ and larger. The main finding of this study is that the metabolic activity of minute metazooplankton organisms, while they are feeding, can now be determined with good precision over a period of hours without any invasion of the experimental vessels.
\end{abstract}

KEY WORDS: Oxygen consumption · Nauplii · Time-series · Oxygen sensor spots

\section{INTRODUCTION}

Copepods (Crustacea: Copepoda) are the most abundant group of multicellular organisms on our planet (Mauchline 1998). Their early juveniles, the nauplii, are their most abundant representatives (Fryer 1986). Copepod nauplii, as well as their older relatives, occur in every region of our oceans. Traditionally, nauplii have been underrepresented in taxonomical (Björnberg 1986), oceanographic, and experimental studies (e.g. Paffenhöfer 1998). Thus, our knowledge of nauplii, specifically those of marine planktonic species, is far more limited than that of older juveniles and adults.

Planktonic nauplii are vulnerable to food shortages because, compared to older juveniles and adults, they possess hardly any energy reserves (e.g. Lee et al. 1972). Therefore, we are interested not only in how much they can ingest at environmental food levels, but also to what extent the ingested amount covers their metabolic expenditures and needs for growth. To date, the number of publications on metabolic expenditures of nauplii of planktonic copepods is limited (Klekowski et al. 1977, Epp \& Lewis 1979).

Traditional quantifications of energy consumption on such tiny animals, most of which are continuous movers, have encountered methodological difficulties. The use of oxygen consumption as a measure of energy expenditures has typically required small volumes of water in order to achieve a measurable decrease in oxygen concentration. Thus, to date, the Cartesian Diver microrespirometry method, developed by Holter (1943) and Zeuthen (1953), has been applied to determine oxygen consumption of copepod nauplii and older stages (e.g. Klekowski 1977, Epp \& Lewis 1979, Kiørboe et al. 1985). In all these experiments, the 
volume of water used (on the order of several microliters per nauplius, Klekowski 1977) confined the nauplii and limited their movement. In addition, no food was supplied. All experiments were characterized by quantifying oxygen concentration at the start and end of each experiment. The above-mentioned limitations could be overcome by utilizing larger vessel volumes and offering food at environmental concentrations while quantifying the changes in oxygen concentration with sufficient precision.

During the last decade, optical fluorescence-based sensors for the measurement of dissolved oxygen concentration have been receiving increasing interest (e.g. Klimant \& Wolfbeis 1995, Holst et al. 2000, Wolfbeis 2004), especially for biological applications (e.g. Klimant et al. 1997, Holst \& Mizaikoff 2002, Viollier et al. 2003). They measure the fluorescence intensity and/or the fluorescence lifetime of an oxygen-sensitive dye that adheres to each sensor's surface (Klimant et al. 1995). Because of their high sensitivity, their ability to measure low oxygen concentrations with a high precision, their driftless signals, and their application to microscales, optical fluorescence-based oxygen sensors are advantageous compared to traditional electrochemical oxygen sensors. Recently, the development and optimization of sensor materials for optical sensing of oxygen (e.g. Apostolidis et al. 2004) led to the manufacture of small fluorescencebased oxygen sensor spots integrated in commercial microtiter plates (John et al. 2003, Szela \& Marsh 2005), offering the possibility to measure oxygen concentrations non-invasively and simultaneously in a large number of samples. Such sensor systems have been applied to the screening of oxygen-consuming enzymes, the monitoring of aerobic cell respiration (John et al. 2003, Deshpande \& Heinzle 2004) and microbiological degradation of pollutants, and the testing of toxic substances (Deshpande et al. 2005). They might also be valuable tools for monitoring respiration of minute invertebrates.

The goal of this study was to determine the oxygen consumption of copepod nauplii at environmental food concentrations in time-series experiments. As a representative species occurring on the middle and outer shelf off the southeastern USA, we selected the calanoid Eucalanus pileatus (Paffenhöfer 1983). E. pileatus nauplius stages III to VI move continuously and feed on phytoplankton, including the diatom Thalassiosira weissflogii by producing a feeding current (Paffenhöfer \& Lewis 1989). For quantification of oxygen consumption of E. pileatus nauplii during feeding at environmental food concentrations we used an innovative optical fluorescence-based 24-channel oxygen meter. This enabled us to quantify oxygen concentrations non-invasively and simultaneously with a high temporal resolution in vessels in which the nauplii were continuously moving, similar to what they did in larger vessels.

\section{MATERIALS AND METHODS}

Fluorescence-based oxygen measurements. The oxygen consumption of copepod nauplii was measured using optical fluorescence-based oxygen respirometry. An innovative 24-channel oxygen meter (Sensor dish reader SDR2, PreSens) was originally designed to read oxygen in ordinary well cell culture plates (Fig. 1). In this study, we successfully used small glass vessels of 1.4 to $1.7 \mathrm{ml}$ volume (inner diameter of $\sim 14 \mathrm{~mm}$, height of $\sim 10 \mathrm{~mm}$ ) to provide the mostly circularly moving nauplii with space to move well. Unlike ordinary plastic microtiter plates, glass vessels provide a gasimpermeable surface and can be handled separately

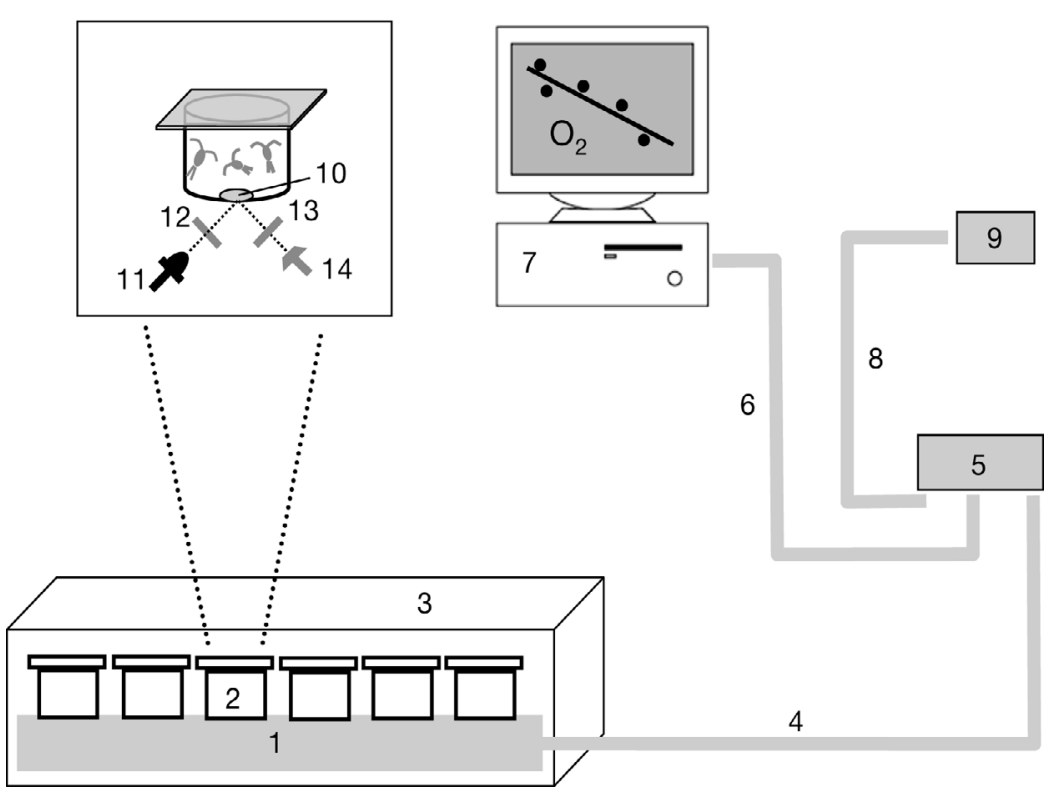

Fig.1. Experimental setup for the optical measurement of dissolved oxygen in miniaturized respiration chambers: (1) 24-channel sensor dish reader, (2) respiration chamber, (3) dark incubator, (4) RJ 45 cable, (5) splitter, (6) connection to PC (RS-232), (7) computer, (8) connection to power adapter, (9) power adapter. The insert reveals the measuring principle in a respiration chamber: (10) planar optode, (11) light-emitting diode, (12) excitation filter, (13) emission filter, (14) photodiode 
for sample pre-treatment. Planar oxygen sensor spots (diameter of $5 \mathrm{~mm}$, with optical isolation, type SP-PSt5NAU-D5-YOP, PreSens) were glued onto the bottom of the glass vessels using silicone rubber sealant (RS Components). The sensor spots consisted of an oxygen-sensitive foil with an immobilized fluorescent dye (ruthenium derivate) and an optical isolation. The measuring principle of the optical-based sensors is based on the fluorescence quenching of organic ruthenium derivates in the presence of oxygen (dynamic fluorescence quenching, Kautsky 1939). The sensor dish reader was connected via a RJ45 cable and a splitter to a PC (Fig. 1). Data were recorded every $5 \mathrm{~min}$. The calibration of the fluorescence-based oxygen sensor spots was performed at $0 \%$ ( $2 \%$ sodium sulfite solution) and $100 \%$ oxygen air saturation in deionized water. The temperature of the measuring device was continuously measured by an internal sensor during the experiments. Generally, the temperature of the device was 0.2 to $0.3^{\circ} \mathrm{C}$ higher than the room temperature.

Rearing of nauplii. Adult copepods of the calanoid Eucalanus pileatus were collected from the middle continental shelf off the southeastern USA in February 2006 when surface temperatures were near 17 to $18^{\circ} \mathrm{C}$. The copepods were separated immediately into seawater collected at the site and kept at temperatures near $20^{\circ} \mathrm{C}$ on board. Later, 1 to 2 fertilized females of E. pileatus were placed in 21 glass jars filled with seawater collected at the sampling site, supplying the diatoms Thalassiosira weissflogii and Rhizosolenia alata and the dinoflagellate Gymnodinium nelsoni, whose combined concentration did not surpass $100 \mu \mathrm{g}$ carbon (C) $\mathrm{l}^{-1}$. The jars were mounted on a plankton wheel (rotation $0.3 \mathrm{rpm}$ ) and incubated at $20^{\circ} \mathrm{C}$ in a temperature-controlled room. Jars were twice daily inspected for hatched nauplii. Young nauplii were transferred into 21 jars containing sea water recently filtered through GF/F filters and food organisms. The above-mentioned 3 phytoplankton species were added, resulting in average concentrations of near $60 \mu \mathrm{g} \mathrm{Cl}^{-1}$.

Nauplii experiments. For each of 3 respiration experimental series, about 20 Eucalanus pileatus nauplii ranging from Nauplius IV to Nauplius VI were transferred to approximately $40 \mathrm{ml}$ of a suspension of Thalassiosira weissflogii (prepared with GF/F filtered sea water) for temperature adaptation (about $1 \mathrm{~h}$ ). Using a cut-off glass pipette, 3 to 4 nauplii were then placed into each of four 1.4 to $1.7 \mathrm{ml}$ glass respiration vessels filled with the same algal suspension as the one they had been placed in initially. The phytoplankton suspensions were similar in abundance to natural phytoplankton concentrations. The filled vessels were closed with glass lids so that no air bubbles were included. Glass vessels were positioned in succession on the sensor dish reader SDR2 (Fig.1). In each experimental series, 4 vessels containing nauplii, and an additional 3 to 4 vessels serving as controls were run simultaneously. The control vessels contained the same diatom suspension that was used for the nauplii. The experiments were run in the dark at $21^{\circ} \mathrm{C}$ over periods of $6 \mathrm{~h}$ in a temperature-controlled room (temperature accuracy $\pm 0.1^{\circ} \mathrm{C}$ ). The control and experimental vessels were not agitated during the $6 \mathrm{~h}$ periods. Change in oxygen concentration in the control jars was always insignificant.

The oxygen consumption of the nauplii in each vessel was calculated from the linear part of time-dependent oxygen concentration curves by linear regression. Individual respiration rates of nauplii were determined after subtracting the average control rates from the individual respiration rates to eliminate net oxygen consumption/production by bacteria and microalgae. To compare respiration activity of different sizes/ stages of nauplii, individual oxygen consumption rates and weight-specific respiration rates were determined and related to the body weight of the nauplii. The daily metabolic expenditures of a nauplius as percentage of its body weight were calculated as follows:

$\mathrm{O}_{2}$ consumption nauplius ${ }^{-1} \mathrm{~d}^{-1}\left(\mathrm{nl} \mathrm{O}_{2} \mathrm{~N}^{-1} \mathrm{~d}^{-1}\right.$ expressed as calories [cal]; $1 \mathrm{ml} \mathrm{O}_{2}=4.86 \mathrm{cal}$, Winberg 1979) divided by nauplius weight (expressed as $\mathrm{Cal}_{\text {; }}$ $1 \mathrm{mg}$ ash-free dry weight $[\mathrm{AFDW}]=5.00 \mathrm{cal}$ ).

After the incubation period, the physiological appearance of nauplii in the respiration vessels was inspected using a stereomicroscope at 25-fold magnification by checking their motion, gut content, and integrity of antennules. Then, the contents of each respiration vessel was transferred into a $10 \mathrm{ml}$ sedimentation chamber and preserved with $5 \%$ final concentration of acid Lugol's solution. Numbers of nauplii faecal pellets, and concentration of algae were determined by inverted microscopy at a 200 -fold magnification. Clearance and ingestion rates were calculated from the difference between initial and final phytoplankton cell concentration and the growth rates of T. weissflogii in the controls (Frost 1972). Daily weight-specific ingestion rates were calculated as (ingestion rate during $24 \mathrm{~h} /$ nauplius weight) $\times 100 \%$. At the end of each experiment the body lengths of the nauplii were measured to the nearest $15 \mu \mathrm{m}$ to classify their stage and to calculate their AFDW. Stages were not always the same within an experiment. To determine the relationship between nauplii body length and body weight (AFDW), we measured the lengths of additional nauplii of different stages (8 samples, ranging from 15 to 29 nauplii) reared on food levels similar to those of the experimental animals. We gently removed excess salt water with blotting paper, dried the nauplii at $60^{\circ} \mathrm{C}$ for 24 to $48 \mathrm{~h}$, weighed them and combusted them at $500^{\circ} \mathrm{C}$ in a muffle furnace, resulting in the AFDW of the respective nauplii. 
Statistics. Linear regression coefficients for timeseries oxygen consumption measurements were calculated in Excel (Microsoft Office 2000).

\section{RESULTS}

All of our time-series measurements of oxygen consumption of nauplii of Eucalanus pileatus lasted $6 \mathrm{~h}$ and were run during daytime while incubating the control and experimental vessels in the dark. Sizes of nauplii ranged from near 400 to near $600 \mu \mathrm{m}$ body length, i.e. Nauplius stages IV to VI. The relation of body length to AFDW was expressed by the equation $\log$ AFDW $=1.997$ (log body length $)-5.094, r^{2}=0.871$, $\mathrm{n}=8, \mathrm{p}<0.001$.

In all our experiments we observed a linear decline in oxygen concentration ( $\mathrm{r}=0.993$ to $1.000, \mathrm{n}=70$ to 76) over a $6 \mathrm{~h}$ period, while in the accompanying controls the concentrations hardly changed (Fig. 2). The decline in oxygen concentration in each vessel ranged from 0.53 to $1.66 \% \mathrm{O}_{2}$ air saturation $\mathrm{h}^{-1}$ (corresponding to 1.19 and $3.73 \mathrm{nmol} \mathrm{O}_{2} \mathrm{ml}^{-1}$, respectively). This means that the oxygen concentrations were reduced by about 3 to $10 \%$ of the initial value during the $6 \mathrm{~h}$ study period. Variations in oxygen consumption were closely related to the number of nauplii per vessel (Fig. 2). Experimental vessels containing 4 nauplii revealed a 1.7 times higher oxygen consumption than those containing 3 nauplii. Differences in oxygen consumption measured in vessels having identical number of individuals varied from 20 to $50 \%$ and were attributed to differences in the size and metabolic activity of individual nauplii.

The individual oxygen consumption increased with increasing body weight from $18.3 \mathrm{nl} \mathrm{O}$ Nauplius $\mathrm{IV}^{-1} \mathrm{~h}^{-1}(1.25 \mu \mathrm{g}$ AFDW) to $32.4 \mathrm{nl} \mathrm{O}$ Nauplius $\mathrm{VI}^{-1} \mathrm{~h}^{-1}$ (2.6 $\mu \mathrm{g}$ AFDW, Fig. 3). The average concentration of Thalassiosira weissflogii in the experimental vessels was $60.6 \mu \mathrm{g}$ $\mathrm{C}^{-1}$, the mean starting concentration 94.6 $\mu \mathrm{C} \mathrm{Cl}^{-1}$, and the mean end concentration $39.8 \mu \mathrm{g} \mathrm{C}^{-1}$ (Table 1). The end concentrations varied because in vessels with 4 nauplii more cells were eaten than in those with fewer nauplii. All these concentrations were in the range of phytoplankton levels encountered often on the southeastern shelf of the USA (e.g. Paffenhöfer 1983). Clearance rates of the nauplii were on average
$0.08 \mathrm{ml} \mathrm{N}^{-1} \mathrm{~h}^{-1}$ which would amount to $1.91 \mathrm{ml} \mathrm{N}^{-1}$ $\mathrm{d}^{-1}$. The average weight-specific ingestion rate was $17.7 \%$ of body weight $d^{-1}$ (Table 2 ). The average rate of faecal pellet production, which can be considered as an indicator of copepod feeding, was 2.2 pellets Nauplius $^{-1} \mathrm{~h}^{-1}$. While quite a few cells of $T$. weissflogii were found at the end of the study periods on the bottom of the control vessels, the experimental vessels had numerous pellets on the bottom but hardly any $T$. weissflogii cells. It is assumed that the continuous motion of the nauplii throughout each vessel prevented settling of those cells.

\section{DISCUSSION}

The main objectives of this study were (1) to demonstrate the ability to continuously quantify with high temporal resolution oxygen consumption of planktonic copepods, (2) to apply this method to copepod nauplii, and (3) to determine oxygen consumption rates of nauplii while feeding. In our experiments we determined the respiration rates of nauplii of marine planktonic copepods continuously under natural food concentra-

(a)

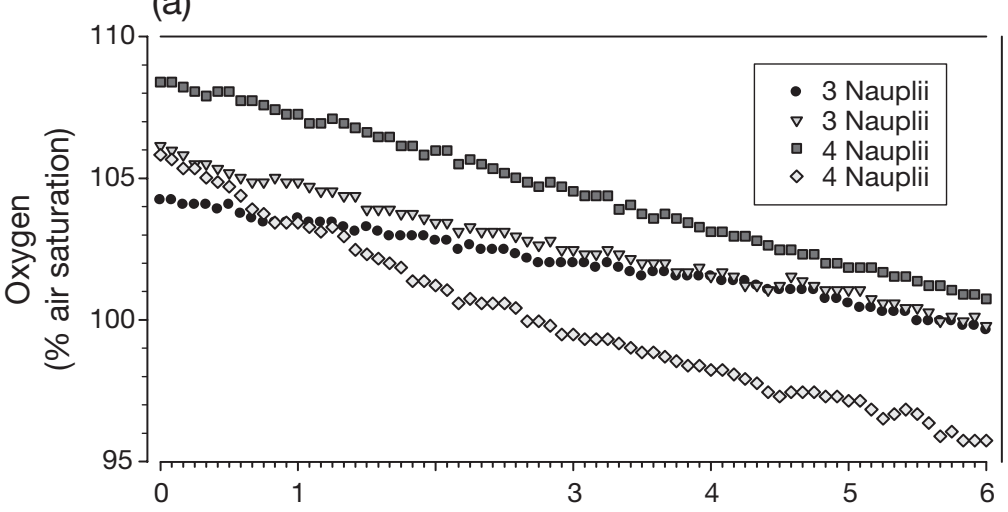

(b)
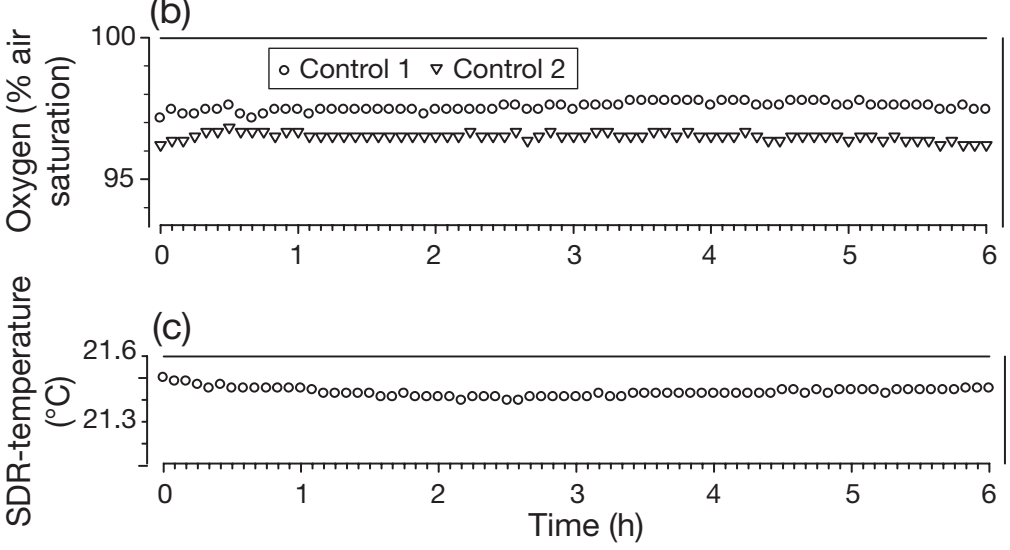

Fig. 2. Eucalanus pileatus. Oxygen concentrations in vessels containing 3 or 4 nauplii and in control vessels over a period of $6 \mathrm{~h}$ at $21.2^{\circ} \mathrm{C}$. SDR: sensor dish reader 


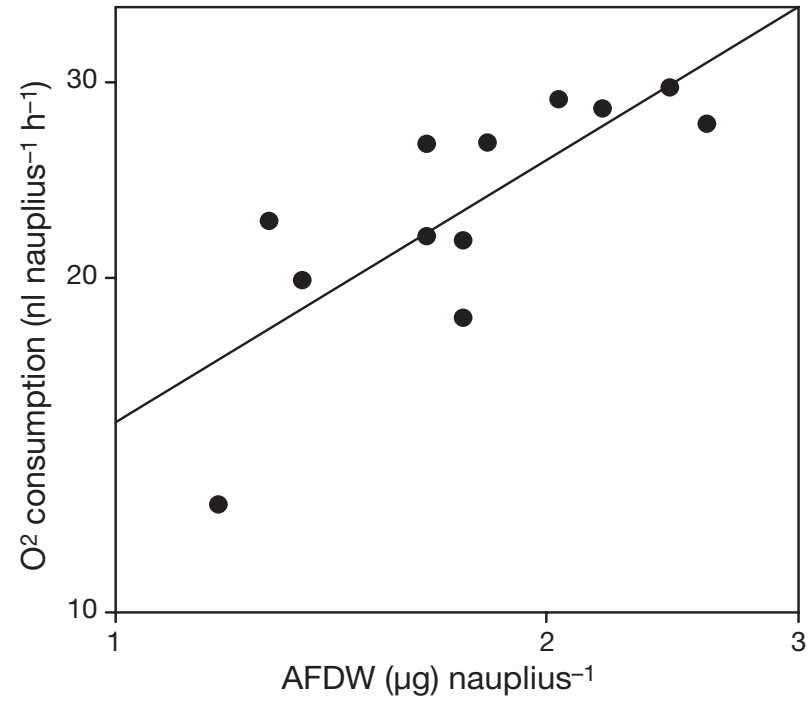

Fig. 3. Eucalanus pileatus. Oxygen consumption in relation to ash-free dry weight (AFDW) of nauplii (log $y=1.187+$ $\left.0.781 \log x, r^{2}=0.616, p<0.01\right)$

Table 1. Thalassiosira weissflogii. Average, initial and final concentrations in the experimental vessels $\left(\mu \mathrm{g} \mathrm{Cl}^{-1}\right)$

\begin{tabular}{|lccc|}
\hline & Average & Initial & Final \\
\hline $\bar{X}$ & 60.6 & 94.6 & 39.8 \\
$\mathrm{n}$ & 11 & 11 & 11 \\
$\mathrm{SD}$ & \pm 10.6 & \pm 4.5 & \pm 12.6 \\
$\mathrm{SE}$ & \pm 3.2 & \pm 1.4 & \pm 3.8 \\
Range & $39-79$ & $89-99$ & $15-64$ \\
\hline
\end{tabular}

Table 2. Eucalanus pileatus. Feeding rates of nauplii at $21^{\circ} \mathrm{C}$

\begin{tabular}{|lccc|}
\hline & \multicolumn{2}{c}{ Clearance rate } & Weight-specific \\
& $\left(\mathrm{ml} \mathrm{N}^{-1} \mathrm{~h}^{-1}\right)$ & $\left(\mathrm{ml} \mathrm{N}^{-1} \mathrm{~d}^{-1}\right)$ & $\begin{array}{c}\text { Westion rate } \\
\text { inges } \\
(\% \text { of body weight d }\end{array}$ \\
& & & \\
\hline $\bar{X}$ & 0.080 & 1.9 & 17.7 \\
$\mathrm{n}$ & 11 & 11 & 11 \\
$\mathrm{SD}$ & \pm 0.015 & \pm 0.36 & \pm 6.0 \\
$\mathrm{SE}$ & \pm 0.005 & \pm 0.12 & \pm 1.8 \\
Range & $0.067-0.118$ & $1.61-2.83$ & $11.1-30.6$ \\
\hline
\end{tabular}

tions while simultaneously obtaining estimates of feeding and faecal pellet production rates.

We had several reasons to focus on nauplii. First, metabolic expenditure data for copepod nauplii are rare. Second, earlier observations had revealed that nauplii of several genera of calanoid copepods did not change their motion behavior when encountering walls of incubation vessels as compared to later copepodid stages (G. A. Paffenhöfer unpubl. data). They appeared to be unaffected when kept in vessels as small as $1.6 \mathrm{ml}$ and were thought to feed regularly. Since the species Eucalanus pileatus had been studied repeatedly in our laboratory (e.g. Paffenhöfer \& Knowles 1978) we were familiar with the behavior of all of its stages. E. pileatus is abundant in neritic waters of subtropical continental shelves (e.g. Binet 1978, Valentin 1980, Paffenhöfer 1983).

\section{Oxygen consumption}

When quantifying oxygen consumption over extended periods the vast majority of measurements on planktonic copepods have been characterized by an initial and an end value that were applied to obtain a respiration rate. Repeated and continuous quantifications of rates of marine zooplankton during a period of time are rare. Results on respiration rates over time are limited to observations on adult females of the copepod Acartia tonsa (Kiørboe et al. 1985), copepodid stage V and adult females of the copepod Calanus finmarchicus (Thor 2002), and nauplii of the brine shrimp Artemia sp. (Szela \& Marsh 2005). Kiørboe et al. (1985) placed 10 to 20 female $A$. tonsa in a chamber of $0.8 \mathrm{ml}$ with a very low flow-through of either filtered seawater (which resulted in starvation conditions) or a food suspension. Intermittent measurements revealed that starving females reduced their initial metabolic rate to near $25 \%$ of the initial rate over $2 \mathrm{~d}$. Thor (2002) applied the same method as Kiørboe et al. (1985) and observed an increase of about $60 \%$ of oxygen consumption for feeding over non-feeding copepods. Szela \& Marsh (2005) applied a methodology similar to ours on individual nauplii or several nauplii of Artemia sp. Artemia nauplii were always in an experimental volume of $40 \mu \mathrm{l}$ over periods of up to $64 \mathrm{~h}$. They observed decreases in oxygen concentration over time. However, their raw data revealed (their Fig. 1) that changes in oxygen concentration were nonlinear during the initial and final phase of the incubation. To determine respiration rates, they selected a time interval of only $2 \mathrm{~h}$, over which oxygen consumption rates were linear. Non-linear decreases in oxygen consumption during initial and final periods indicated that the nauplii of Artemia sp. were influenced by the experimental conditions.

Our results revealed that Nauplius IV to Nauplius VI of Eucalanus pileatus had a constant rate of oxygen consumption over periods of up to 6 h, i.e. the decline in oxygen concentration in the experimental vessels was linear and steady (Fig.2). As food concentrations diminished in the $1.6 \mathrm{ml}$ vessels, the respiration rate of these nauplii seemed to be unaffected.

A comparison of oxygen consumption rates of nauplii and of zooplankton of similar dry weight $(2 \mu \mathrm{g})$, from 
our and other studies, revealed major differences (Table 3) which could be attributed to animal treatment prior to measurements, feeding and motion behavior and methods for the determination of oxygen. Klekowski et al. (1977) determined from the body weight-respiration relationship calculated for nauplii of unknown taxonomy from the eastern Pacific Ocean that nauplii of $2 \mu \mathrm{g}$ dry weight (10 millicalories) respired $9.0 \%$ of their body weight daily at $20^{\circ} \mathrm{C}$. Their measurements were made between 2 to $8 \mathrm{~h}$ after collection with no food offered and were of individual animals confined to several microliters. Epp \& Lewis (1979) studied juveniles of Mesocyclops brasilianus that had been feeding on the alga Chlorella sp. at unknown quantities for several days prior to respiration measurements. At the beginning of each measurement, during which each individual was confined to a several-microliter container (Table 3), their guts were filled. At $24^{\circ} \mathrm{C}$, the rarely moving Nauplius VI respired $19.8 \%$ of its body weight daily, and the Copepodid I (of similar weight but moving frequently) respired $41.4 \%$ of body weight daily. Thus, the energy spent while moving appendages and trying to swim is reflected in metabolic expenditures. Szela \& Marsh (2005) found that 2 to $3 \mathrm{~d}$ old nauplii of the brine shrimp Artemia sp. respired only $3.8 \%$ of their body weight $\mathrm{d}^{-1}$ (Table 3 ), with individuals in their experiment being kept in microtiter plate wells of $40 \mu \mathrm{l}$ volume. This value may be an aberration because those Artemia nauplii may have been starving. According to Reeve (1963) Artemia nauplii have consumed most of their yolk $30 \mathrm{~h}$ after hatching and usually then start to feed.

A comparison of oxygen consumption of zooplankton individuals of similar weight ( $2 \mu \mathrm{g}$ of dry weight) from body weight-respiration relationships found $17.2 \%$ of body weight respired per $\mathrm{d}$ for various zooplankton taxa and $23.6 \%$ respired per $d$ for epipelagic plank- tonic copepods (Ikeda 1985, Ikeda et al. 2001, Table 3). Those animals had been kept in unfiltered seawater in volumes of $4 \mathrm{ml}$ and larger for less than $24 \mathrm{~h}$ prior to the measurements. Copepodid stage $\mathrm{V}$ (female) of Mesocyclops brasilianus with full guts prior to measurements respired $22.8 \%$ of their body weight daily (Table 3). Our result for late nauplii of Eucalanus pileatus (an average of $29.7 \%$ of body weight respired daily) exceeds all cited results of zooplankton of similar weight and is in the upper range of values obtained for epipelagic copepods by Ikeda et al. (2001).

Why would the nauplii of E. pileatus consume so much more oxygen than the other taxa? The following citations suggest that the availability and utilization of food could have contributed to the differences. For a non-feeding female of the estuarine copepod Acartia tonsa, Kiørboe et al. (1985) reported an oxygen consumption rate of near $8 \mu \mathrm{O}_{2}$ mg dry weight ${ }^{-1} \mathrm{~h}^{-1}$ at $18^{\circ} \mathrm{C}$ (their Fig. 6). That rate amounts to $18.8 \%$ of body weight respired per $\mathrm{d}$, whereas an Acartia tonsa female feeding at about $50 \mu \mathrm{g} \mathrm{C} \mathrm{l}^{-1}$ of food would have respired ca. $140 \%$, and at $100 \mu \mathrm{g} \mathrm{C} \mathrm{l}^{-1}$ ca. $210 \%$ of its body weight daily (from Fig. 7 of Kiørboe et al. 1985). These authors attributed the increased respiration rates to specific dynamic action (SDA) which was thought to be associated with increasing feeding rates, and according to them can be expressed relative to ingestion or assimilation rates. Thor (2002, his Fig. 1) showed an increase in respiration rates of Calanus finmarchicus Copepodid V within several hours of food addition of about $60 \%$ over that of nonfeeding copepods, which decreased to pre-feeding levels after about $8 \mathrm{~h}$ of food deprivation. He attributes the increase in respiration rate of feeding $C$. finmarchicus over the rate of pre-feeding copepods (without food for $2 \mathrm{~d}$ ) to SDA, which is associated with the formation of new body mass. Svetlichny \&

Table 3. Weight-specific oxygen consumption rates of zooplankton. N VI: Nauplius stage VI; C I: Copepodid stage I; C V (F): Copepodid stage of future female

\begin{tabular}{|c|c|c|c|c|c|c|}
\hline Species & $\begin{array}{l}\text { Volume of } \\
\text { vessel }\end{array}$ & $\begin{array}{c}\text { Temperature } \\
\text { of incubation } \\
\left({ }^{\circ} \mathrm{C}\right)\end{array}$ & $\begin{array}{l}\text { Dry weight } \\
\text { ( } \mu \text { g per } \\
\text { animal) }\end{array}$ & $\begin{array}{c}\mathrm{O}_{2} \text {-Consumption } \\
(\% \text { body } \\
\left.\text { weight } \mathrm{d}^{-1}\right)\end{array}$ & Method & Source \\
\hline Planktonic nauplius & $0.02-100 \mu \mathrm{l}$ & 20 & 2 & 9.0 & Cartesian diver & Klekowski et al. (1977) \\
\hline Mesocyclops & $1-14 \mu \mathrm{l}$ & 24 & 0.165 N VI & 19.8 N VI & Cartesian diver & Epp \& Lewis (1979) \\
\hline brasilianus & & & $0.18 \mathrm{C} \mathrm{I}$ & $41.4 \mathrm{C} \mathrm{I}$ & & \\
\hline $\begin{array}{l}\text { (nauplius to late } \\
\text { copepodid) }\end{array}$ & & & $1.5 \mathrm{C} \mathrm{V}(\mathrm{F})$ & $22.8 \mathrm{C} \mathrm{V}(\mathrm{F})$ & & \\
\hline Marine zooplankter & $\geq 4 \mathrm{ml}$ & 20 & 2 & 17.2 & Winkler titration & Ikeda (1985) \\
\hline Planktonic copepod & $\geq 4 \mathrm{ml}$ & 20 & 2 & 23.6 & Winkler titration & Ikeda et al. (2001) \\
\hline $\begin{array}{l}\text { Artemia sp. } \\
\text { (nauplius) }\end{array}$ & $40 \mu \mathrm{l}$ & $21-23$ & $\sim 1.65$ & 3.8 & $\mathrm{O}_{2}$-Optode & Szela \& Marsh (2005) \\
\hline $\begin{array}{l}\text { Eucalanus pileatus } \\
\text { (nauplius) }\end{array}$ & $1.6 \mathrm{ml}$ & 21 & 2 & 29.7 & $\mathrm{O}_{2}$-Optode & Present study \\
\hline
\end{tabular}


Huboreva (2005), studying the energetics of $C$. euxinus, observed that offering food to starved copepods increased their locomotory activity, which resulted in an increase in respiration rate. They found that increases in metabolism due to SDA varied with activity level of the copepods.

\section{Feeding rates at environmental food concentrations}

Since the condition of zero food particles does not occur for marine zooplankton in its natural environment, and since our approach was ecologically oriented, we decided to offer environmentally realistic food abundances at the beginning of each experiment, when the nauplii had been preconditioned to such food species and levels. Despite offering food levels which in earlier studies amounted to a daily ration of about $50 \%$ of body weight (Paffenhöfer \& Knowles 1978), the daily food consumption by Eucalanus pileatus nauplius stages IV to VI in the present study amounted on average to only $17.7 \%$ of their body weight. A nauplius of E. pileatus of about $2.0 \mu \mathrm{g}$ AFDW had swept clear between 2 to $10 \mathrm{ml} \mathrm{d}^{-1}$ depending on cell size (Paffenhöfer \& Knowles 1978), while in the present study such rates ranged between 1.5 to $2.8 \mathrm{ml} \mathrm{d}^{-1}$ at comparable food levels. It appears that E. pileatus nauplii in the experimental vessels of around $1.6 \mathrm{ml}$, despite their seemingly regular motion, were limited in their feeding rate as compared to those in Paffenhöfer \& Knowles (1978), which were in vessels of 2000 to $3500 \mathrm{ml}$ volume. This assumption is supported by O'Brien (1988), who found that the clearance rates of the rapidly moving predaceous copepod Heterocope septentrionalis increased 42.5 times when container size was increased from 0.3 to $54 \mathrm{l}$. Thus, quantifications of metabolic expenditures on free-swimming copepods are probably related to the extent that they are confined spatially.

The bottom line of our findings is that in our (and previous) respiration studies the copepods could have been limited in their food intake because of spatial limitations. In all previous oxygen consumption studies, when food was offered, the actual ingestion rate was not quantified. The question remains whether the respiration rate of our nauplii, which had been kept earlier in non-restricting vessel volumes and at environmental food levels, was immediately affected by spatial limitations in such small respiration chambers. The findings by Kiørboe et al. (1985, their Fig. 6) seem to indicate that a pronounced decrease in oxygen consumption of starved females of Acartia tonsa started only several hours after that experiment was initiated. Therefore, zero food intake should have manifested itself most likely only after several hours in reduced respiration rates, and that of limited food intake, as in our experiments, probably even later.

\section{Production of faecal pellets}

In previous studies with nauplii of Eucalanus pileatus faecal pellet production ranged from 50 to 120 pellets $\mathrm{N}^{-1} \mathrm{~d}^{-1}$ at an ingestion rate of about $180 \mu \mathrm{g} \mathrm{Cl}^{-1}$ which amounts to about 2 to 5 pellets $\mathrm{N}^{-1} \mathrm{~h}^{-1}$ (Paffenhöfer \& Knowles 1979). The pellet release rates in our study of 2.2 pellets $\mathrm{N}^{-1} \mathrm{~h}^{-1}$ were in the lowest part of that range. The actual number of pellets produced per hour is, however, an inaccurate expression of the amount of content of organic matter released since faecal pellets can vary widely in their size and content (e.g. Paffenhöfer \& Köster 2005).

\section{CONCLUSIONS}

Our results demonstrate that use of fluorescencebased oxygen sensor spots permits the quantification of minute decreases of oxygen concentration over time. This method can be applied to determine the oxygen consumption of metazooplankton in small and large vessels while the animals are starving or feeding. This should allow us to address the following questions:

(1) To what extent does vessel volume affect respiration rates, i.e. does a small vessel volume immediately (within several min to hours) affect the regular respiration rate of a zooplankter which had been previously feeding in an unrestricted volume, e.g. in situ? The larger the vessel, the larger the volume to wall area ratio!

(2) How will different ingestion rates and associated motion affect respiration rates when the vessel volume is not limiting?

(3) To what extent will a planktonic copepod perform metabolically once it encounters food shortages? That should be of particular interest for nauplii which are thought to have few energy reserves.

By answering these questions, the extent of validity of previous oxygen quantifications in limited volumes can be addressed, and the extent of energy consumption of zooplankton living at a range of environmental food concentrations and respective ingestion rates can be evaluated, i.e. simulating in situ conditions.

Acknowledgements. Thomas Horn, Ernst-Moritz-Arndt-Universität, Greifswald, Germany, manufactured the glass vessels for our oxygen consumption studies. The captain and crew of the R/V 'Savannah' contributed to collecting planktonic copepods. The National Science Foundation supported our study with a grant (OCE 99-00315). Their support is gratefully acknowledged. 


\section{LITERATURE CITED}

Apostolidis A, Klimant I, Andrzejewski D, Wolfbeis OS (2004) A combinatorial approach for development of materials for optical sensing of gases. J Comb Chem 6:325-331

Binet D (1978) Analyse globale des populations de copepodes pelagiques du plateau continental ivoirien. Cah ORSTOM Oceanogr 16:19-61

Björnberg TKS (1986) The rejected nauplius: a commentary. Syllogeus 58:232-236

Deshpande RR, Heinzle E (2004) On-line oxygen uptake rate and culture availability measurement of animal cell culture using microplates with integrated oxygen sensors. Biotechnol Lett 26:763-767

Deshpande RR, Kirsch Y, Maas R, John GT, Krause C, Heinzle E (2005) Microplates with integrated oxygen sensors for kinetic cell respiration measurement and cytotoxicity testing in primary and secondary lines. ASSAY Drug Dev Technol 3:299-307

Epp RW, Lewis WM Jr (1979) Metabolic responses to temperature change in a tropical freshwater copepod (Mesocyclops brasilianus) and their adaptive significance. Oecologia (Berlin) 42:123-138

Frost BW (1972) Effects of size and concentration of food particles on the feeding behaviour of the marine planktonic copepod Calanus pacificus. Limnol Oceanogr 17: 805-815

Fryer G (1986) Structure, function and behaviour, and the elucidation of evolution in copepods and other crustaceans. Syllogeus 58:150-157

Holst G, Mizaikoff B (2002) Fiber optic sensors for environmental applications. In: Lopez-Higuera JM (ed) Handbook of optical fibre sensing technology. Wiley, Chichester, p 729-755

Holst G, Klimant I, Kühl M, Kohls O (2000) Optical microsensors and microprobes. In: Varney MS (ed) Chemical sensors in oceanography. Gordon \& Breach, Amsterdam, p 143-188

Holter H (1943) Techniques of the Cartesian diver. C R Trav Lab Carlsb, Ser Chim 24:399-478

Ikeda T (1985) Metabolic rates of epipelagic marine zooplankton as a function of body mass and temperature. Mar Biol 85:1-11

Ikeda T, Kanno Y, Ozaki K, Shinada A (2001) Metabolic rates of epipelagic marine copepods as a function of body mass and temperature. Mar Biol 139:587-596

John GT, Klimant I, Wittmann C, Heinzle E (2003) Integrated optical sensing of dissolved oxygen in microtiter plates: a novel tool for microbial cultivation. Biotechnol Bioeng 81: 829-836

Kautsky H (1939) Quenching of luminescence by oxygen. Trans Fariday Soc 35:216-219

Kiørboe T, Møhlenberg F, Hamburger K (1985) Bioenergetics of the planktonic copepod Acartia tonsa: relation between feeding, egg production and respiration, and composition of specific dynamic action. Mar Ecol Prog Ser 26:85-97

Klekowski RZ (1977) Microrespirometer for shipboard measurements of metabolic rate of microzooplankton. Pol Arch Hydrobiol 24(Suppl):455-465

Klekowski RZ, Kukina IV, Tumanseva NI (1977) Respiration in the microzooplankton of the equatorial upwellings in

Editorial responsibility: Barry and Evelyn Sherr (Contributing Editors), Corvallis, Oregon, USA the eastern Pacific Ocean. Pol Arch Hydrobiol 24(Suppl): 467-489

Klimant I, Wolfbeis OS (1995) Oxygen-sensitive luminescent materials based on silicone-soluble ruthenium diimine complexes. Anal Chem 67:3160-3166

Klimant I, Meyer V, Kühl M (1995) Fiber-optic oxygen microsensors, a new tool in aquatic biology. Limnol Oceanogr 40:1159-1165

Klimant I, Kühl M, Glud RN, Holst R (1997) Optical measurement of oxygen and temperature in microscale: strategies and biological applications. Sensor Actuator 38:29-37

Lee RF, Nevenzel JC, Paffenhöfer GA (1972) The presence of wax esters in marine planktonic copepods. Naturwiss 59: $406-411$

Mauchline J (1998) The biology of calanoid copepods. Adv Mar Biol 33:1-710

O'Brien, WJ (1988) The effect of container size on the feeding rate of Heterocope septentrionalis, a freshwater predaceous copepod. J Plankton Res 10:313-317

Paffenhöfer GA (1983) Vertical zooplankton distribution on the northeastern Florida shelf and its relation to temperature and food abundance. J Plankton Res 5:15-33

Paffenhöfer GA (1998) On the relation of structure, perception and activity in marine planktonic copepods. J Mar Syst 15:457-473

Paffenhöfer GA, Knowles SC (1978) Feeding of marine planktonic copepods on mixed phytoplankton. Mar Biol 48: 143-152

Paffenhöfer GA, Knowles SC (1979) Ecological implications of fecal pellet size, production and consumption by copepods. J Mar Res 37:35-49

Paffenhöfer GA, Köster M (2005) Digestion of diatoms by planktonic copepods and doliolids. Mar Ecol Prog Ser 297: 303-310

Paffenhöfer GA, Lewis KD (1989) Feeding behavior of nauplii of the genus Eucalanus (Copepoda, Calanoida). Mar Ecol Prog Ser 57:129-136

Reeve MR (1963) Growth efficiency in Artemia under laboratory conditions. Biol Bull 125:133-145

Svetlichny LS, Huboreva ES (2005) The energetics of Calanus euxinus: locomotion, filtration of food and specific dynamic action. J Plankton Res 27:671-682

Szela TL, Marsh AG (2005) Microtiter plate, optode respirometry, and inter-individual variance in metabolic rates among nauplii of Artemia sp. Mar Ecol Prog Ser 296: 281-289

Thor P (2002) Specific dynamic action and carbon incorporation in Calanus finmarchicus copepodites and females. J Exp Mar Biol Ecol 272:159-169

Valentin J (1980) L'écosystème d'upwelling à Cabo Frio (Brésil). Analyse en composantes principales du plancton à une station fixe. Oceanol Acta 3:43-50

Viollier E, Rabouille C, Apitz SE, Breuer E and others (2003) Benthic biogeochemistry: state of the art technologies and guidelines for the future of in situ survey. J Exp Mar Biol Ecol 285-286:5-31

Wolfbeis OS (2004) Biannual review on fiber optic chemical sensors and biosensors (2002-2003). Anal Chem 76: $3269-3283$

Zeuthen E (1953) Oxygen uptake as related to body size in organisms. Quart Rev Biol 28:1-12

Submitted: January 2, 2007; Accepted: July 31, 2007

Proofs received from author(s): December 25, 2007 